\title{
Transmission of Surfactant Protein Variants and Haplotypes in Children Hospitalized With Respiratory Syncytial Virus
}

\author{
NEAL J. THOMAS, SUSAN DIANGELO, JOSEPH C. HESS, RUZONG FAN, MARGARET W. BALL, JOSEPH M. GESKEY, \\ DOUGLAS F. WILLSON, AND JOANNA FLOROS
}

\begin{abstract}
Departments of Pediatrics [N.J.T., S.D., J.C.H., J.M.G., J.F.], Public Health Sciences [N.J.T.], and Obstetrics and Gynecology [J.F.], Pennsylvania State University College of Medicine, Hershey, Pennsylvania 17033; Department of Statistics [R.F.], Texas A\&M University, College Station, Texas 77843; Department of Pediatrics [M.W.B., D.F.W.], University of Virginia, Charlottesville, Virginia 22908
\end{abstract}

\begin{abstract}
Severity of lung injury with respiratory syncytial virus (RSV) infection is variable and may be related to genetic variations. This preliminary report describes a prospective, family-based association study of children hospitalized secondary to RSV, aimed to determine whether intragenic and other haplotypes of surfactant proteins (SP)-A and SP-D are transmitted disproportionately from parents to offspring with RSV disease. Genomic DNA was genotyped for several SP-A and SP-D single nucleotide polymorphisms (SNPs). Transmission disequilibrium test analysis was used to determine transmission of variants and haplotypes from parents to affected offspring. Three hundred seventy-five individuals were studied, including 148 children with active RSV disease and one or both parents. The SP-A2 intragenic haplotype $1 \mathrm{~A}^{2}$ was found to be protective ( $p=0.013)$. The SP-D SNP DA160_A may possibly be an "at-risk" marker $(p=0.0058)$. Additional two- and three-marker haplotypes were associated with severe RSV disease, with two being protective (DA11_T/DA160_G and DA160_G/ SP-A2 $1 \mathrm{~A}^{\%} / \mathrm{SP}-\mathrm{A} 16 \mathrm{~A}^{2}$ ). We conclude that there may be associations between SP-A and SP-D and RSV disease. Further study is required to determine whether these variants can be used to target a high-risk patient population in clinical trials aimed at reducing either the symptoms of acute infection or long-term pulmonary sequelae. (Pediatr Res 66: 70-73, 2009)
\end{abstract}

$\mathrm{R}$ espiratory syncytial virus infection (RSV) is the most common cause of hospitalization in infants. This remains true despite the fact that other viruses such as rhinoviruses (1) and metapneumovirus (2) are increasingly associated with lower respiratory tract infections. Virtually all children acquire RSV infection in the first 2 y of life, and 2-3\% become ill enough to be hospitalized, and $5-10 \%$ of these will require mechanical ventilation (3-5). In the United States, $\mathrm{RSV}$ is the most common viral cause of death in children younger than 5 y (6). Several risk factors for severe disease have been identified, including premature birth, congenital heart disease, neurologic disorders, bronchopulmonary dys-

\footnotetext{
Received March 24, 2008; accepted February 2, 2009

Correspondence: Neal J. Thomas, M.D., Pediatric Critical Care Medicine, Penn State Children's Hospital, 500 University Drive, MC H085, Hershey, PA 17033; e-mail: nthomas@psu.edu

Supported by research grants from The American Lung Association (CG-971-N), National Institutes of Health (HL34788: Penn State University and R01CA133996; M.D. Anderson Cancer Center), and Children's Miracle Network of Penn State Children's Hospital.

Presented at The Society of Critical Care Medicine's 35th Educational and Scientific Symposium, Orlando, FL, February 17-21, 2007.
}

plasia, other preexisting lung disorders, immunosuppression, and genetic syndromes, among others (7-11). However, healthy children still make up a large proportion of children hospitalized secondary to RSV, particularly since the availability of palivizumab, a humanized MAb that is administered prophylactically to these high-risk children (12). In healthy children, infection with RSV causing bronchiolitis early in life has been found to associate with subsequent wheezing and an asthma-like phenotype (13-16). Although it remains unclear whether lung disease is a sequelae of or a risk factor for early RSV infection, determining any genetic predisposition to severe infection would be important in attempting to prevent both acute and chronic sequelae. To that goal, several studies have identified links between polymorphisms of genes crucial to the immune response and acute symptoms of severe RSV disease. These include toll like receptor-4, CD 14 (17), IL-4 and IL-4 receptor alpha (18), IL-10 (19), and chemokine receptor CCR5 (20), among others. Genetic variants of the surfactant proteins (SP) have only been studied in limited fashion $(21,22)$.

Because of constant exposure of the lung to viruses, bacteria, and antigens, an effective innate immune response is necessary before the development of specific adaptive immunity. The pulmonary surfactant system plays a key role in this innate immune response. Four SPs, SP-A, -B, -C, and -D, compose the protein portion of pulmonary surfactant and SP-A and SP-D are important in the innate immune response $(23,24)$, including host defense functions aimed at protection against viral infections such as RSV. The human SP-A locus consists of two functional genes (SP-A1 and SP-A2) in opposite transcriptional orientation (25). SP-A and SP-D protein levels are decreased in bronchoalveolar lavage fluid of infants with RSV (26). SP-A knock out mice infected with RSV have greater inflammation and increased viral titers when compared with wild-type mice, and this inflammation is reduced when exogenous SP-A is administered (27). SP-A interacts with an SP-A receptor on alveolar macrophages to enhance ingestion of pulmonary pathogens and has been shown to augment

\footnotetext{
Abbreviations: RSV, respiratory syncytial virus; SP-A, surfactant protein-A; SP-D, surfactant protein-D; SNP, single nucleotide polymorphism; TDT, transmission disequilibrium test; ETDT, extended transmission disequilibrium test
} 
uptake of RSV in monocytes and macrophage-like cells via binding to the G-attachment protein of RSV (28). Moreover, SP-D knock out mice display decreased RSV clearance and increased inflammation after RSV infection, demonstrating that SP-D also plays a crucial role in the innate immune response against RSV infection (29). Additionally, in a homogenous study group, SP-A and SP-D variants were identified as risk factors for RSV $(21,22)$.

Taken together, these data point to the potential importance of genetic variations of these two proteins to the development of severe RSV disease in infants. Therefore, we undertook this pilot study to investigate the hypothesis that known variants and novel genetic haplotypes of SP-A and SP-D are transmitted disproportionately from parents to young children affected with severe RSV requiring hospitalization.

\section{METHODS}

Genomic DNA was extracted from whole blood samples or buccal swabs from children admitted with a primary diagnosis of RSV disease at two academic children's hospitals, Penn State Children's Hospital and University of Virginia Children's Hospital, during three consecutive winters. Buccal swab samples were also collected from one or both parents during the hospitalization. The protocol for the collection and use of human samples in this study was approved by the Human Subjects Protection Office of The Pennsylvania State University College of Medicine and the Institutional Review Board for Health Sciences Research at The University of Virginia, and informed consent was obtained from each parent or guardian. The diagnosis of RSV was made by either direct fluorescent assay or viral culture of nasopharyngeal swabs. Clinical data on all children were extracted from the medical records.

Genomic analysis. DNA was extracted from $200 \mu \mathrm{L}$ of blood or buccal swab using QIAamp DNA mini kit (Qiagen, Valencia, CA) according to manufacturer's instructions. The genomic DNA served as a template for PCR in the genotype analysis. All samples were genotyped for SP-A and SP-D using a pyrosequencing method that has been previously described in detail by our group (30).

Statistical analysis. The nuclear family based transmission disequilibrium test (TDT) analysis was performed using GENEHUNTER (www.broad.mit. edu) (Whitehead Institute for Biomedical Research, MIT) to determine: a) transmission of individual SP (SP-A and SP-D) markers from parents to affected offspring and b) transmission of haplotypes of two-, three-, and four-marker loci (31). TDT measures the frequency of transmission of a single

Table 1. Demographics of study population of children admitted secondary to respiratory syncytial virus disease

\begin{tabular}{lc}
\hline \multicolumn{1}{c}{ Characteristic } & $(n=148)$ \\
\hline Age, mo [median (IQR)] & $2.3(1.3-7.3)$ \\
Female sex, $n(\%)$ & $72(49)$ \\
Race or ethnic group, $n(\%)$ & \\
White & $102(69)$ \\
Black & $7(5)$ \\
Hispanic & $24(16)$ \\
Other & $15(10)$ \\
Premature $<35$ wk, $n(\%)$ & $21(14)$ \\
Cardiac disease, $n(\%)$ & $7(5)$ \\
Previous lung disease, $n(\%)$ & $12(8)$ \\
\hline
\end{tabular}

nucleotide polymorphism (SNP) or haplotype from a heterozygous parent to the affected child and the nontransmitted SNP or haplotype serves as an internal control. Logistic regression, performed by extended TDT (ETDT) analysis (32), was also performed and yielded consistent results with TDT. Statistical significance was defined as $p<0.05$. Additional analyses on transmitted and untransmitted alleles were performed using the exact test, using QuickCals software (http://graphpad.com/quickcalcs/binomial1.cfm).

\section{RESULTS}

A total of 375 individuals composed the study population. This included 148 children who required hospital admission secondary to RSV disease, and one or both parents. Demographic data describing the study population of children are shown in Table 1 . Thirty-seven percent $(n=55)$ of children had severe enough respiratory distress to require pediatric intensive care unit admission, and $22 \%(n=32)$ of the study population required endotracheal intubation and assisted mechanical ventilation.

TDT analysis suggested that specific SP-A and SP-D alleles and haplotypes might be linked to severe RSV infection. One SP-A and one SP-D variant were found to associate with the development of severe RSV disease (Table 2). The SP-A2 intragenic haplotype $1 \mathrm{~A}^{2}$ was found to be protective, with only two children having this variant transmitted from a heterozygous parent to affected offspring and 12 children not having it transmitted (asymptotic $p=0.008$; exact $p=0.013$ for TDT). The SP-D SNP DA160_A may be an "at-risk" variant, with 35 alleles transmitted and only 20 not being transmitted from heterozygous parents (asymptotic $p=0.043$; exact $p=0.058$ for TDT). Regression analysis with ETDT was also performed to further assess linkage of the multipleallele loci with RSV. For ETDT, we tested the hypothesis of no linkage between RSV and the SP-A1, SP-A2, and SP-D loci by examining two models, a parsimonious (allele-wise) and a saturated (genotype-wise). Goodness of fit testing showed adequacy of the allele-wise model compared with the saturated model. Allele-wise ETDT analysis provided confirming evidence that SP-A2 (asymptotic $p=0.042$, likelihood ratio test, $5 \mathrm{df}$ ) and the SNP AA-160 (asymptotic $p=$ $0.042,1 \mathrm{df}$ ) are linked to severe RSV infection.

Haplotypes of SP-A1, SP-A2, and SP-D were also examined for transmission from parents to affected children. Table 3 demonstrates that 2 two- and three-marker haplotypes were associated with protection against the development of severe RSV disease (DA11_T/DA160_G and DA160_G/SP-A2 1A\% SP-A1 6A ${ }^{2}$ ). Three haplotypes (DA160_A/SP-A2 1 $\mathrm{A}^{2}$,

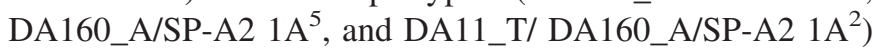
may also be associated with either risk or protection from RSV disease, but the modest sample size of this study precludes a decisive conclusion due to the small number of haplotypes transmitted and untransmitted (Table 3).

Table 2. Transmission of surfactant protein variants from parents to offspring hospitalized with respiratory syncytial virus

\begin{tabular}{|c|c|c|c|c|c|c|}
\hline \multirow[b]{2}{*}{ Gene } & \multirow[b]{2}{*}{ Allele } & \multirow[b]{2}{*}{ Impact } & \multirow[b]{2}{*}{ Transmitted } & \multirow[b]{2}{*}{ Untransmitted } & \multicolumn{2}{|c|}{ TDT $p$ values } \\
\hline & & & & & Asymptotic & Exact \\
\hline SP-A2 & $1 \mathrm{~A}^{2 *}$ & Protection & 2 & 12 & 0.008 & 0.013 \\
\hline SP-D & DA160_A $\dagger$ & Risk & 35 & 20 & 0.043 & 0.058 \\
\hline
\end{tabular}

* Signifies intragenic haplotype.

$\dagger$ Signifies single nucleotide polymorphism DA160_A = the SP-D Amino Acid 160_A. This SNP changes the codon for amino acid 160 from GCA (Ala) to ACA (Thr). 
Table 3. Haplotype analysis of the surfactant protein genes on the development of respiratory syncytial virus infection requiring hospitalization

\begin{tabular}{|c|c|c|c|c|c|}
\hline \multirow[b]{2}{*}{ Haplotype } & \multirow[b]{2}{*}{ Impact } & \multirow[b]{2}{*}{ Transmitted } & \multirow[b]{2}{*}{ Untransmitted } & \multicolumn{2}{|c|}{ TDT $p$ values } \\
\hline & & & & Asymptotic & Exact \\
\hline \multicolumn{6}{|l|}{ Two marker analysis } \\
\hline DA160_A/SP-A2 1A ${ }^{2}$ & Protection & 0 & 4 & 0.045 & 0.125 \\
\hline DA160_A/SP-A2 $1 \mathrm{~A}^{5}$ & Risk & 4 & 0 & 0.045 & 0.125 \\
\hline DA11_T/DA160_G & Protection & 11 & 24 & 0.028 & 0.041 \\
\hline \multicolumn{6}{|l|}{ Three marker analysis } \\
\hline DA11_T/DA160_A/SP-A2 1A ${ }^{2}$ & Protection & 0 & 4 & 0.045 & 0.125 \\
\hline DA160_G/SP-A2 $1 \mathrm{~A}^{0} / \mathrm{SP}-\mathrm{A} 16 \mathrm{~A}^{2}$ & Protection & 9 & 21 & 0.028 & 0.043 \\
\hline
\end{tabular}

\section{DISCUSSION}

SP-A and SP-D play important roles in innate host defense in the lung, and have been implicated in the pathogenesis of RSV via findings from studies of SP-A and SP-D knockout mice $(27,29)$, associations of genetic variants of these genes with RSV susceptibility in Finnish study groups $(21,22)$, and alterations in SP content in lung alveolar fluid in infants with RSV (26). In this preliminary study, a family-based transmission association approach was used to investigate the hypothesis that SP-A and SP-D susceptibility variants are transmitted disproportionally from parent to affected child. The findings demonstrate, for the first time, that transmission of SNPs and haplotypes of SP-A and SP-D from parents to affected offspring may influence the development of severe RSV disease. We have identified SNPs as well as haplotypes of genes on chromosome 10 that seem to influence the development of RSV lung disease serious enough to warrant hospitalization in young children. If confirmed, the markers identified here may be used to identify children at high risk for the development of respiratory failure from RSV who could benefit from more aggressive therapy at the onset of symptoms.

The protective effect of the SP-A2 intragenic haplotype $1 \mathrm{~A}^{2}$ is a novel finding compared with the previous genetic studies performed in a Finnish population. Moreover, this variant, when examined in prematurely born infants with respiratory distress syndrome (RDS) using a similar family-based association testing, was found to also trend $(p=0.06)$ toward protection against this lung disease (33). Although differences in the degree of stimulation of phagocytosis of bacteria have been observed between SP-A1 and SP-A2 gene products (34), it is unknown whether differences in the SP-mediated host response to RSV exists. However, our findings provide some support for those of the Finnish study regarding the finding of the SP-A2 $1 \mathrm{~A}^{3}$ variant (data not shown), which was twice as likely to be transmitted to children with RSV, albeit this did not reach statistical significance due to the small number of $1 \mathrm{~A}^{3}$ haplotypes present. A possible risk to the development of severe RSV in children in which the SP-D allele DA160_A was transmitted was observed. In the DA160 (A/G) SNP, the nucleotide alteration to an A (160_A) from a G (160_G) leads to a change to threonine from alanine in amino acid 160 , which is located in the carbohydrate recognition domain of SP-D. It should be noted that the observation of the DA160_A being a risk factor is in contrast with a previous study on premature infants with RDS, where haplotypes containing the DA160_A allele were protective (35).
Differences of SP variants inferring protection in RDS and risk in other lung diseases (or the converse) have been previously observed, most notably for the SP-A intergenic haplotype $6 \mathrm{~A}^{2} / 1 \mathrm{~A}^{0}$, or the intragenic $6 \mathrm{~A}^{2}$ or $1 \mathrm{~A}^{0}$ haplotypes $(33,36,37)$. No significant observations were made in this study for the DA11_T SNP, or the SP-A2 1A haplotype identified previously as RSV susceptibility factors (21). These apparent discrepancies may reflect differences in ethnic homogeneity, stratification, or other factors. Although coupled by function and also proximity, being mapped to a short region on chromosome $10(25,38,39)$, a three-marker linkage disequilibrium (LD) analysis revealed significant LD in several ethnic groups between the SP-D and SP-A loci (40). In this study, a two- and a three-marker haplotype (DA11_T/DA160_G and DA160_G/SP-A2 1A $\%$ SP-A1 $6 \mathrm{~A}^{2}$ ) were identified to potentially associate with protection of severe RSV disease. These preliminary data indicate that the microenvironment in different lung disease states may influence the susceptibility or protection of certain variants. Alternatively, different processes may be operative in RDS compared with RSV disease, and these may explain the observations.

The TDT analysis tests each allele/haplotype individually, and therefore raises the question of validity in the face of multiple testing. For the concerns of multiple testing, we performed ETDT analysis, which comprehensively tests a marker as a whole and therefore resolves multiple testing issues within a marker, as it tests if a marker is linked with RSV, not a specific allele. The objective of the article was to identify potential protective/risk markers/alleles and haplotypes that are linked to the development of RSV. In this modest preliminary study, we simply report, by TDT analysis, those alleles/haplotypes that show significant results or results that require duplication in a separate population and a larger sample size. We clearly recognize the chance for false positives and know that these data require duplication in a separate population and a larger sample size. Given the nature of such a preliminary pilot study, it is beyond our capability at this point to offer more definite results.

There are some limitations to this pilot study. The moderate sample size may miss important genetic associations. However, this study is the largest family-based RSV association study to date, and therefore, it can serve as a reference for future study. Furthermore, the focus on the acute, severe phase of RSV excludes consideration of the role of these genetic variants on long-term pulmonary function as well as to mild 
RSV disease. Examining all children admitted to the hospital with RSV disease provides a heterogeneous study group. However, this was done to allow us to generalize our results to all children hospitalized with RSV who may be studied in an interventional trial. Limiting the study to a phenotypically similar group of children would have greatly limited the results. This study only examined SP-A and SP-D genetics. Recent reports have demonstrated that genetic alleles of SPs, SP-B and SP-C, known to be important in the surfactanttension lowering properties of surfactant, may also be associated with the development of severe lung disease $(41,42)$. We intend to genotype the samples in our database in the future to confirm or refute these findings.

In conclusion, we have demonstrated for the first time a potential association between haplotypes of SP-A and SP-D and the development of severe RSV disease. These results are preliminary in nature and require verification in a distinct and more extensive population of children infected with RSV. Further study is necessary to determine whether these SP variants can identify a high-risk patient population for interventional clinical trials to reduce either the acute symptoms or the long-term pulmonary sequelae of this early infection. Additional studies are required to determine whether these variants predict disease severity. However, the findings from this preliminary study provide a good foundation, or "proof of principle" for hypothesis generation and investigation in future studies, where important interventional and/or therapeutic strategies may be considered.

\section{REFERENCES}

1. Kusel MM, de Klerk NH, Holt PG, Kebadze T, Johnston SL, Sly PD 2006 Role of respiratory viruses in acute upper and lower respiratory tract illness in the first year of life: a birth cohort study. Pediatr Infect Dis J 25:680-686

2. Wolf DG, Greenberg D, Kalkstein D, Shemer-Avni Y, Givon-Lavi N, Saleh N, Goldberg MD, Dagan R 2006 Comparison of human metapneumovirus, respiratory syncytial virus and influenza A virus lower respiratory tract infections in hospitalized young children. Pediatr Infect Dis J 25:320-324

3. Hall CB 2001 Respiratory syncytial virus and parainfluenza virus. N Engl J Med 344:1917-1928

4. Leader S, Kohlhase K 2003 Recent trends in severe respiratory syncytial virus (RSV) among US infants, 1997 to 2000. J Pediatr 143:S127-S132

5. Holman RC, Curns AT, Cheek JE, Bresee JS, Singleton RJ, Carver K, Anderson LJ 2004 Respiratory syncytial virus hospitalizations among American Indian and Alaska Native infants and the general United States infant population. Pediatrics 114:e437-e444

6. Thompson WW, Shay DK, Weintraub E, Brammer L, Cox N, Anderson LJ, Fukuda K 2003 Mortality associated with influenza and respiratory syncytial virus in the United States. JAMA 289:179-186

7. Purcell K, Fergie J 2004 Driscoll Children's Hospital respiratory syncytial virus database: risk factors, treatment and hospital course in 3308 infants and young children, 1991 to 2002. Pediatr Infect Dis J 23:418-423

8. Boyce TG, Mellen BG, Mitchel EF Jr, Wright PF, Griffin MR 2000 Rates of hospitalization for respiratory syncytial virus infection among children in medicaid. J Pediatr 137:865-870

9. Arnold SR, Wang EE, Law BJ, Boucher FD, Stephens D, Robinson JL, Dobson S, Langley JM, McDonald J, MacDonald NE, Mitchell I 1999 Variable morbidity of respiratory syncytial virus infection in patients with underlying lung disease: a review of the PICNIC RSV database. Pediatric Investigators Collaborative Network on Infections in Canada. Pediatr Infect Dis J 18:866-869

10. Hall CB, Powell KR, MacDonald NE, Gala CL, Menegus ME, Suffin SC, Cohen HJ 1986 Respiratory syncytial viral infection in children with compromised immune function. N Engl J Med 315:77-81

11. Fjaerli HO, Farstad T, Bratlid D 2004 Hospitalisations for respiratory syncytial virus bronchiolitis in Akershus, Norway 1993-2000: a population-based retrospective study. BMC Pediatr 4:25

12. Geskey JM, Thomas NJ, Brummel GL 2007 Palivizumab: a review of its use in the protection of high risk infants against respiratory syncytial virus (RSV). Biol Targets Ther 1:33-43

13. Sigurs N, Bjarnason R, Sigurbergsson F, Kjellman B 2000 Respiratory syncytial virus bronchiolitis in infancy is an important risk factor for asthma and allergy at age 7. Am J Respir Crit Care Med 161:1501-1507
14. Stein RT, Sherrill D, Morgan WJ, Holberg CJ, Halonen M, Taussig LM, Wright AL, Martinez FD 1999 Respiratory syncytial virus in early life and risk of wheeze and allergy by age 13 years. Lancet 354:541-545

15. Carlsen KH, Larsen S, Orstavik I 1987 Acute bronchiolitis in infancy. The relationship to later recurrent obstructive airways disease. Eur J Respir Dis 70:86-92

16. Carlsen KH, Larsen S, Bjerve O, Leegaard J 1987 Acute bronchiolitis: predisposing factors and characterization of infants at risk. Pediatr Pulmonol 3:153-160

17. Puthothu B, Forster J, Heinzmann A, Krueger M 2006 TLR-4 and CD14 polymorphisms in respiratory syncytial virus associated disease. Dis Markers 22:303-308

18. Hoebee B, Rietveld E, Bont L, Oosten M, Hodemaekers HM, Nagelkerke NJ, Neijens HJ, Kimpen JL, Kimman TG 2003 Association of severe respiratory syncytial virus bronchiolitis with interleukin-4 and interleukin-4 receptor alpha polymorphisms. J Infect Dis 187:2-11

19. Wilson J, Rowlands K, Rockett K, Moore C, Lockhart E, Sharland M, Kwiatkowski D, Hull J 2005 Genetic variation at the IL10 gene locus is associated with severity of respiratory syncytial virus bronchiolitis. J Infect Dis 191:1705-1709

20. Hull J, Rowlands K, Lockhart E, Moore C, Sharland M, Kwiatkowski D 2003 Variants of the chemokine receptor CCR5 are associated with severe bronchiolitis caused by respiratory syncytial virus. J Infect Dis 188:904-907

21. Lofgren J, Ramet M, Renko M, Marttila R, Hallman M 2002 Association between surfactant protein A gene locus and severe respiratory syncytial virus infection in infants. J Infect Dis 185:283-289

22. Lahti M, Lofgren J, Marttila R, Renko M, Klaavuniemi T, Haataja R, Ramet M, Hallman M 2002 Surfactant protein D gene polymorphism associated with severe respiratory syncytial virus infection. Pediatr Res 51:696-699

23. Floros J, Phelps DS 1997 Pulmonary surfactant. In: Yaksch TL, Lynch C, Maze M, Biebuyck JF, Saidman LJ (eds) Anesthesia: Biological Foundations. LippincottRaven, New York, pp 1257-1279

24. Phelps DS 1995 Pulmonary surfactant modulation of host-defense function. Appl Cardiopul Pathophysiol 5:221-229

25. Hoover RR, Floros J 1998 Organization of the human SP-A and SP-D loci at 10q22-q23. Physical and radiation hybrid mapping reveal gene order and orientation. Am J Respir Cell Mol Biol 18:353-362

26. Kerr MH, Paton JY 1999 Surfactant protein levels in severe respiratory syncytial virus infection. Am J Respir Crit Care Med 159:1115-1118

27. Levine AM, Gwozdz J, Stark J, Bruno M, Whitsett J, Korfhagen T 1999 Surfactant protein-A enhances respiratory syncytial virus clearance in vivo. J Clin Invest 103:1015-1021

28. Barr FE, Pedigo H, Johnson TR, Shepherd VL 2000 Surfactant protein-A enhances uptake of respiratory syncytial virus by monocytes and U937 macrophages. Am J Respir Cell Mol Biol 23:586-592

29. Levine AM, Elliott J, Whitsett JA, Srikiatkhachorn A, Crouch E, DeSilva N, Korfhagen T 2004 Surfactant protein-d enhances phagocytosis and pulmonary clearance of respiratory syncytial virus. Am J Respir Cell Mol Biol 31:193-199

30. Pavlovic J, Papagaroufalis C, Xanthou M, Liu W, Fan R, Thomas NJ, Apostolidou I, Papathoma E, Megaloyianni E, DiAngelo S, Floros J 2006 Genetic variants of surfactant proteins A, B, C, and D in bronchopulmonary dysplasia. Dis Markers 22:277-291

31. Kruglyak L, Daly MJ, Reeve-Daly MP, Lander ES 1996 Parametric and nonparametric linkage analysis: a unified multipoint approach. Am J Hum Genet 58:13471363

32. Sham PC, Curtis D 1995 An extended transmission/disequilibrium test (TDT) for multi-allele marker loci. Ann Hum Genet 59:323-336

33. Floros J, Fan R, Matthews A, DiAngelo S, Luo J, Nielsen H, Dunn M, Gewolb IH, Koppe J, van Sonderen L, Farri-Kostopoulos L, Tzaki M, Ramet M, Merrill J 2001 Family-based transmission disequilibrium test (TDT) and case-control association studies reveal surfactant protein A (SP-A) susceptibility alleles for respiratory distress syndrome (RDS) and possible race differences. Clin Genet 60:178-187

34. Mikerov AN, Wang G, Umstead TM, Zacharatos M, Thomas NJ, Phelps DS, Floros J 2007 Surfactant protein A2 (SP-A2) variants expressed in CHO cells stimulate phagocytosis of Pseudomonas aeruginosa more than do SP-A1 variants. Infect Immun 75:1403-1412

35. Thomas NJ, Fan R, DiAngelo S, Hess JC, Floros J 2007 Haplotypes of the surfactant protein genes $\mathrm{A}$ and $\mathrm{D}$ as susceptibility factors for the development of respiratory distress syndrome. Acta Paediatr 96:985-989

36. Ramet M, Haataja R, Marttila R, Floros J, Hallman M 2000 Association between the surfactant protein A (SP-A) gene locus and respiratory-distress syndrome in the Finnish population. Am J Hum Genet 66:1569-1579

37. Ramet M, Lofgren J, Alho OP, Hallman M 2001 Surfactant protein-A gene locus associated with recurrent otitis media. J Pediatr 138:266-268

38. Floros J, Hoover RR 1998 Genetics of the hydrophilic surfactant proteins A and D Biochim Biophys Acta 1408:312-322

39. Kolble K, Lu J, Mole SE, Kaluz S, Reid KB 1993 Assignment of the human pulmonary surfactant protein D gene (SFTP4) to 10q22-q23 close to the surfactant protein A gene cluster. Genomics 17:294-298

40. Liu W, Bentley CM, Floros J 2003 Study of human SP-A, SP-B and SP-D loci: allele frequencies, linkage disequilibrium and heterozygosity in different races and ethnic groups. BMC Genet 4:13

41. Puthothu B, Krueger M, Heinze J, Forster J, Heinzmann A 2006 Haplotypes of surfactant protein $\mathrm{C}$ are associated with common paediatric lung diseases. Pediatr Allergy Immunol 17:572-577

42. Puthothu B, Forster J, Heinze J, Heinzmann A, Krueger M 2007 Surfactant protein B polymorphisms are associated with severe respiratory syncytial virus associated diseases. BMC Pulm Med 7:6 